\title{
Ischiopagus Conjoined Twins delivered Vaginally
}

\author{
${ }^{1}$ Ruchika Garg, ${ }^{2}$ Rachna Agrawal, ${ }^{3}$ Saroj Singh, ${ }^{4}$ Mohita Agrawal
}

\begin{abstract}
Conjoint twins (CTs) are a very rare entity since it occurs only once in 50,000 to 2 lakh births. Female:male CTs are 3:1. Conjoint twins are monozygotic twins. In this sense, they share the same zygote where the twinning is initiated after 12 days of fertilization of egg. It may be due to genetic or environmental factors; $40 \%$ of CTs are stillborn and an additional one-third die within 24 hours of birth. We report an undiagnosed case of ischiopagus-tetrapus CTs delivered vaginally, with difficulty needing bilateral episiotomy. The bodies of two fetuses were fused laterally from mid-abdomen to pelvis along with single umbilical cord. There were two heads, four separate limbs, with fusion at pelvic region, and partially fused male external genitalia. The CTs were cyanosed and stillborn. Postnatal period was uneventful.
\end{abstract}

Keywords: Conjoint twins, Episiotomy, Ischiopagus.

How to cite this article: Garg R, Agrawal R, Singh S, Agrawal $M$. Ischiopagus Conjoined Twins delivered Vaginally. World J Anemia 2018;2(1):31-33.

\section{Source of support: Nil}

Conflict of interest: None

\section{INTRODUCTION}

Conjoint twins are one of the most interesting congenital malformations in a twin, although rare occurrence in obstetric practice with the incidence of about 1:50,000 to 1:200,000 births approximately. ${ }^{1}$ Females predominate over males in the order of 2:1 to 3:1. Ischiopagus conjoined twinning is even rarer, representing only $6 \%$ of all CTs. Because of the highly variable and complex anatomy and associated malformations, skilled clinical assessment aided by detailed radiological studies, appropriate planning, and team work are required for the successful separation of the CTs. ${ }^{2,3}$ The management of a case diagnosed late in labor is very challenging. Such a case has high perinatal mortality and maternal morbidity. We present here a case of ischiopagus tetrapus CTs, who passed away while being delivered.

\footnotetext{
1,2,4 Associate Professor, ${ }^{3}$ Professor and Head

${ }^{1-4}$ Department of Obstetrics and Gynecology, Sarojini Naidu Medical College, Agra, Uttar Pradesh, India

Corresponding Author: Ruchika Garg, Associate Professor Department of Obstetrics and Gynecology, Sarojini Naidu Medical College, Agra, Uttar Pradesh, India, e-mail: ruchikagargagra@ gmail.com
}

\section{CASE REPORT}

Mrs. P, a 29-year-old unbooked nulliparous with history of one abortion, reported to emergency labor room at 34 weeks of gestation with complaint of premature labor pain and leaking $\mathrm{p} / \mathrm{v}$ for 4 hours. She was in second stage of labor. There was no history of consanguineous marriage or previous twin in her family. There was no history of ingestion of drugs, contraceptive pills, ovulationinducing agents, or X-ray exposure. She was diagnosed as twin pregnancy by a general practitioner at 30 weeks of gestation. Blood group was AB positive. She had no prenatal medical checkup.

On examination, the woman was of average build and nutrition. Systemic examination was normal; blood pressure was $130 / 80 \mathrm{~mm} \mathrm{Hg}$ in right arm in supine position. She had mild anemia and mild pedal edema. The P/A examination revealed abdomen was overdistended with multiple fetal parts, fundal height was corresponding to 36 weeks, uterine contraction present as 2/10. The Fetal Health Surveillance (FHS) was $110 / \mathrm{min}$ irregular. On investigations, hemoglobin was $9 \mathrm{gm} / \mathrm{dL}$.

At the time of presentation to the hospital, $\mathrm{P} / \mathrm{V}$ cervix was fully dilated, caput present, head at -1 station, membranes absent, liquor thick, and meconium stained. Patient's relative did not give consent for cesarean section as we explained poor prognosis of fetus distress. Yet at that time we were also not aware of CTs as she had no ultrasound report with her. A liberal mediolateral episiotomy was given, and with gentle traction head was delivered followed by chest, shoulder, and upper limbs. Thereafter labor came to a standstill, i.e., no descent with further traction, umbilical cord was felt along with indefinite large mass, and second baby's head was felt. The FHS could not be clinically auscultated by this time. Suspecting CT episiotomy on other side was given after consent and explanation to her relatives. Along with traction rest of the body and second head was delivered. Both fetuses' faces were cyanosed. Both died after 5 minutes. Uterus was examined: There was no cervical tear or detectable injuries. Neonate was found to be with two heads, four arms, four legs, one fused pelvis common umbilical cord, and separate anal openings. Face and extremities were cyanosed. Ischiopagus twins combined weight was $4.7 \mathrm{~kg}$. There was single placenta with two arteries and one vein. Placenta was monochorionic and weighed $550 \mathrm{gm}$. Autopsy was not permitted by relatives. Photograph 
and radiograph were taken. Radiographic examination showed two heads, two vertebral columns, fusion of lower half at the level of pelvis. The mother had an uneventful postpartum course and was discharged on third day after delivery.

\section{DISCUSSION}

Conjoined twins are always derived from one fertilized ovum and are monochorionic (shared placenta) and monoamniotic (Quiroz et al; Hammond et al). ${ }^{4}$ They occur once in 50,000 to 2 lakh deliveries. More commonly called Siamese twin as this word was first used for the celebrated pair of CTs, Chang and Eng Bunker, who died at the age of 63 in North California, 1874. Most authors report 70 to $95 \%$ of CTs are female (Barth et al), ${ }^{5}$ though one study cited a nearly equal male:female ratio (Castillo et al). ${ }^{6}$ Spencer proposed a classification for CTs based on the site of union, i.e., ventral or anterior union (cephalopagus, thoracopagus, omphalopagus, ischiopagus, and parapagus) and dorsal or posterior union (craniopagus, pyopagus, and rachipagus), while Potter and Craig simply classified based on the most common forms of twinning. ${ }^{7,8}$ Grossly, ischiopagus usually lie along a long axis with heads on opposite sides. They have a common umbilicus and the bodies fuse below this level, sharing lower abdomen and pelvis. About half of the ischiopagus have four separate lower limbs, one-third have three lower limbs (two separate and one fused) attached to the body laterally and onefifth of the cases are parasitic. ${ }^{2,3,7,8}$ Our case, therefore, is an example of ischiopagus tetrapus (Fig. 1). Turner et $\mathrm{al}^{9}$ remarked magnetic resonance imaging is superior to computed tomography, due to the lack of exposure to radiation during antenatal period. ${ }^{8}$ Imaging methods, as technology advances, provide more opportunities to reach to diagnosis. Criteria for ultrasonography (USG) diagnosis of CTs include absence of separating amniotic

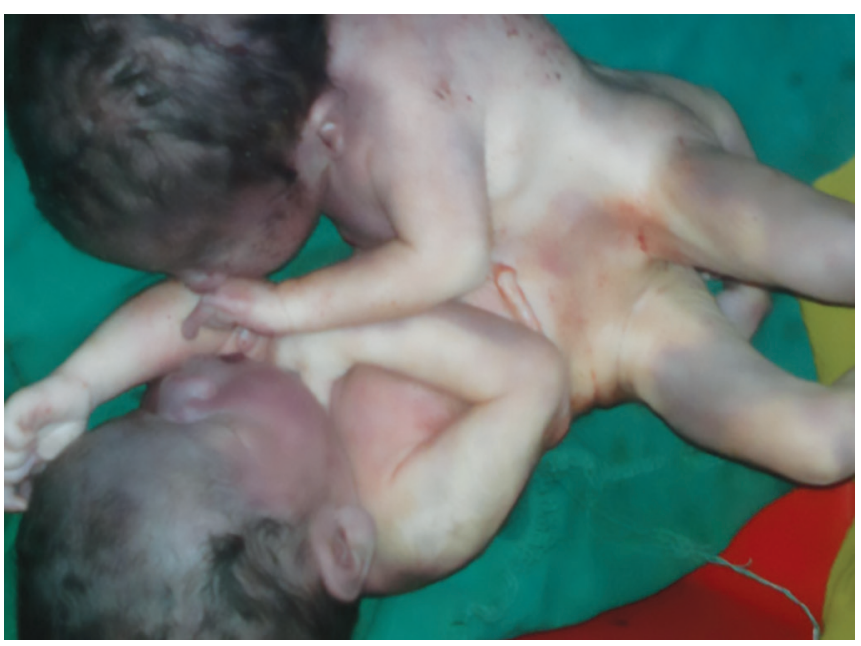

Fig. 1: Ischiopagus conjoined twins after delivery membrane, inseparable fetal bodies, lack of change of relative positions of bodies and fetal heads on repeated examinations, heads at the same level and body plane, unusual proximity/hyperextensions of spines, unusual proximity of limbs, bifid appearance of the first trimester fetal pole complex anomalies, and more than three umbilical vessels. ${ }^{1}$ Polyhydramnios is present in 50 to $76 \%$ cases. Diagnosis of CTs is hard and requires an experienced perinatologist. Especially monochorionic-monoamniotic CTs make USG technically harder. The USG in early weeks is really important. One of the diagnostic methods, three-dimensional Doppler USG, is an effective method for better understanding of the family as the existing pathology and shows a way about continuation or termination of pregnancy.

\section{CONCLUSION}

The diagnosis of CTs can be made at mid-pregnancy by a thorough targeted USG scan with careful evaluation of the point of connection and organs involved. When the CTs are identified before birth, cesarean section is preferred to avoid maternal trauma and to facilitate treatment of viable neonates. However, vaginal delivery may be attempted with small, very premature, or nonviable fetuses, with pregnancy termination before 24 weeks of gestation (Bart et al). ${ }^{10}$ Prognosis of these twins depends on the nature and extent of organ sharing and presence of other malformations. In general, few CTs survive, due to heart, lung, abdominal, neurological malformations often present even in unshared structures.

\section{REFERENCES}

1. Daskalakis G, Pilalis A, Tourikis I, Moulopoulos G, Karamoutzous I, Antsaklis A. First trimester diagnosis of dicephalous conjoined twins. Eur J Obstet Gynecol Reprod Biol 2004 Jan;112(1):110-113.

2. Sangari SK, Khatri K, Pradhan S. Omphalopagus ischiopagus tetrapus conjoined twins-a case report. J Anat Soc India 2001;50(1):40-42.

3. Zhang XS, Feng ZG, Xiong QX, Li MJ, Tang DX. Successful separation of ischiopagus tetrapus conjoined twins. World J Pediatr 2007 Aug;3(3):228-231.

4. Quiroz VH, Sepulveda WH, Mercado M, Bermudez R, Fernandez R, Varela J. Prenatal ultrasonographic diagnosis of thoracopagus conjoined twins. J Perinat Med. 1989;17: 297-303.

5. Barth RA, Filly RA, Goldberg JD, Moore P, Silverman NH. Conjoined twins: pre-natal diagnosis and assessment of associated malformations. Radiology. 1990;177:201-207.

6. Castillo RA, Cuevas E, Arias D, Dominguez CA, MolinaFreaner $F$. The genetic structure of the gynodioecious Kallstroemia grandiflora (Zygophyllaceae): the role of male sterility and colonization history. Heredity. 2006;97:269-674. 
7. Spencer R. Anatomic description of conjoined twins: a plea for standardized terminology. J Pediatr Surg 1996 Jul;31(7): 941-944.

8. O'Neill, JA Jr. Conjoined twins. In: O’Neill JA Jr, Rowe MI, Grosfeld JL, Fonkalsrud EW, Coran AG, editors. Pediatric surgery. 6th ed. Philadelphia (PA): Mosby; 2006. p. 2080.
9. Turner RJ, Hankins GDV, Weinreb JC, et al. Magnetic resonance imaging and ultrasonography in the antenatal evaluation of conjoined twins. Am J Obstet Gynecol. 1986;155:645-649.

10. Bart Y, Bartal MF, Sibai BM, Shina A, Mazaki-Tovi S, Eisen IS, Hendler I, Baum M, Schiff E. The Impact of Sperm and Egg Donation on the Risk of Pregnancy Complications. Am J Perinatol. 2018 Jul 21. doi: 10.1055/s-0038-1667029. 